DOI: $10.14451 / 2.132 .39$

\title{
КОНЦЕПТУАЛИЗАЦИЯ МЕЖДУНАРОДНО-ПРАВОВОГО РЕГУЛИРОВАНИЯ НАУЧНО-ТЕХНИЧЕСКОГО СОТРУДНИЧЕСТВА *
}

\author{
(c) 2019 Шулятьев Игорь Александрович \\ кандидат юридических наук, старший преподаватель кафедры международного и европейского права \\ Институт законодательства и сравнительного правоведения \\ при Правительстве Российской Федерации, Россия, Москва \\ E-mail: iash7@mail.ru
}

Решение проблем научно-технического развития стало частью глобальной повестки развития. Усложнение цепочки «наука - инновации - промышленность» повышает роль правового регулирования и значение норм международного права. В настоящей статье автор рассматривает общие требования к современному международно-правовому регулированию научно-технического сотрудничества, которые могут быть использованы для разработки правовой модели практического взаимодействия в области науки и техники на международном уровне.

Ключевые слова: наука, международное право, международно-правовое регулирование, научная дипломатия, академическая свобода, суверенитет, Евразийская патентная конвенция.

Международное научно-техническое сотрудничество в современном мире выступает как объективная закономерность развития и функционирования международных отношений. Научная деятельность, взятая в международном измерении, представляет собой сложный комплекс общественных отношений со своей предметной областью, участниками и нормативной системой. Развитие международной научной кооперации зависит от уровней и структуры современной системы межгосударственных отношений: глобальный уровень, региональный и субрегиональный уровни, уровень международно-политической ситуации, уровень групповых (коалиционных и межкоалиционных) отношений, уровень двусторонних отношений государств, а также наличия неправительственного сектора международных отношений, частью которого является так называемая научная дипломатия. Экономические и научнотехнические отношения составляют одно из наиболее существенных по значению подсистем полиструктурной системы межгосударственных отношений. Рассматривая их взаимосвязи с политическими отношениями, с которыми она особенно тесно взаимодействует, крайне трудно, если вообще возможно, разделить отношения экономические и научно-технические, настоль- ко тесно они переплетены [1].

Современная наука не только несет человечеству новые знания, она становится все более важным фактором практического преобразования мира [2]. В резолюции Генеральной Ассамблеии ООН 70/1 от 25 сентября 2015 года «Преобразование нашего мира: повестка дня в области устойчивого развития на период до 2030 года» сказано, что «распространение информационно-коммуникационных технологий и глобальное взаимное подключение сетей, как и научно-технические инновации в столь разных областях, как медицина и энергетика, открывают огромные возможности для ускорения человеческого прогресса, преодоления «цифрового разрыва» и формирования общества, основанного на знаниях, а также для развития» (пункт 15) [3]. Первенство в исследованиях и разработках, высокий темп освоения новых знаний и создания инновационной продукции являются ключевыми факторами, определяющими конкурентоспособность национальных экономик и эффективность национальных стратегий безопасности.

Международное научное и научнотехническое сотрудничество является частью международных экономических отношений и, как правило, имеет единую международно-

\footnotetext{
* статья подготовлена в рамках гранта РФФИ на реализацию научного проекта № 18-29-15005 «Исследование правового регулирования международного научного и научно-технического сотрудничества, международной интеграции в области научных исследований и технологического развития и разработка правовой модели участия РФ в этих процессах, включая использование средств и методов научной дипломатии»
} 
правовую базу в виде многосторонних и двусторонних договоров о торгово-экономическом взаимодействии государств. Международная научная кооперация предусматривает создание и реализацию крупных технологических проектов, направленных на получение фундаментальных и прикладных результатов исследовательской деятельности. Значение международно-правового регулирования научно-технического сотрудничества заключается в установлении механизмов, процедур, прав и обязанностей, ответственности государств и создании благоприятных правовых, организационных и экономических условий для исследователей. Научная тема о соотношении международного права и научно-технического прогресса имеет глубокие корни в отечественной международно-правовой доктрине и обладает широкой перспективой для дальнейших исследований, например, в области изучения правовых механизмов научной дипломатии.

Наука - это сложное общественное явление. Прежде всего, наука является одной из форм общественного сознания,- непосредственно связанной с производственной практикой. Наука может быть определена и как накопленная система знаний о природе, обществе, мышлении. Далее, наука - это средство раскрытия законов природы для удовлетворения потребностей общества. И наконец, наук есть особая сфера человеческой деятельности, и вид общественного разделения труда, большой общественный институт с собственной системой отношений и учреждений, со своей материальной базой, системой подготовки кадров, их специализацией, службой информации и т.д. При определении науки в целом все перечисленные характеристики (стороны) науки должны быть неразрывно связаны одна с другой, должны существовать в единстве. Однако при исследовании того или иного аспекта науки как сложного общественного явления на первый план выступает какая-нибудь одна сторона или несколько сторон [4].

В международно-правовом понимании, слово «наука» означает деятельность, с помощью которой человечество, индивидуально либо небольшими или большими группами, предпринимает организованную попытку путем объективного изучения наблюдаемых явлений открыть и овладеть причиной цепью; сводит воедино в координированной форме получающиеся в результате подсистемы знания путем систематического отражения и объяснения с помощью понятий, часто в значительной степени выражаемых математическими символами; и посредством этого обеспечивает себе возможность использовать в своих интересах понимание процессов и явлений, происходящих в природе и общества [5].

Творческое и продуктивное развитие науки и научной деятельности обеспечивается международным принципом академической свободы. Свободное распространение информации о результатах, гипотезах и критических высказываниях - что подразумевается под выражением «академическая свобода» - является неотъемлемой частью научного процесса и обеспечивает наибольшую гарантию точности и объективности научных результатов [5]. Творческая деятельность научно-исследовательских работников должна поощряться национальной политикой в области науки на основе строго соблюдения автономии свободы исследований, необходимых для научного прогресса (п. 8) [5].

Крупные политические, экономические и социальные перемены и научный прогресс, которые произошли в мире со времени принятия Устава Организации Объединенных Наций, повышают значение основных принципов международного публичного права и необходимость их более эффективного применения в деятельности государств в научно-технической сфере По своему генезису международно-правовые принципы и нормы могут быть разбиты на две категории: принципы и нормы, не связанные непосредственно с техникой и техническим прогрессом (суверенитет, невмешательство, равенство и др.); принципы и нормы, прямо или косвенно связанные с техникой и техническим прогрессом. Как показывает исторический опыт, влияние технического прогресса на принципы и нормы второй категории может быть двояким. Прежде всего, технический прогресс может служить расширению сферы применения общепризнанных основных принципов международного права. Таково, например, положение с утверждением принципа суверенитета на воздушное пространство государств, возникшего в связи с изобретением воздухоплавательных аппаратов и распространением общего принципа суверенитета государства на его воздушное пространство. Сюда же можно отнести расширение сферы действия, содержания и понятия принципа ненападения, который ныне предполагает не толь- 
ко воздержание от нападения, но и воздержание от подготовки к нападению посредством наращивания технического потенциала, заблаговременного создания военных баз за пределами границ государства-агрессора и до. Технический прогресс, кроме того, может содействовать появлению и становлению новых международноправовых принципов и норм, таких, например, как принципы демилитаризации и нейтрализации, принцип разоружения и др. В исторической перспективе таковым был и принцип свободы морей, возникший в связи с освоением и развитием техники мореплавания [6].

Важное значение имеют положения Декларации об использовании научно-технического прогресса в интересах мира и на благо человечества [7]. Все государства содействуют международному сотрудничеству в целях использования результатов научно-технического прогресса в интересах укрепления международного мира и безопасности, свободы и независимости, а также в целях экономического и социального развития народов и обеспечения прав и свобод человека в соответствии с Уставом Организации Объединенных Наций. Все государства принимают соответствующие меры, с тем чтобы предотвратить использование достижений науки и техники, в частности государственными органами, для ограничения или вмешательства в осуществление прав человека и основных свобод, провозглашенных во Всеобей декларации прав человека, Международных пактах о правах человека и других соответствующих документах. Все государства принимают меры, направленные на то, чтобы достижения науки и техники служили целям удовлетворения материальных и духовных потребностей всех слоев населения. Все государства воздерживаются от любых действий, влекущих использование научно-технических достижений для нарушения суверенитета и территориальной неприкосновенности других государств, вмешательства в их внутренние дела, ведения агрессивных войн, подавления национально-освободительных движений, проведения политики расовой дискриминации. Такие действия не только являются грубым нарушением Устава Организации Объединенных Наций и принципов международного права, но и представляют собой недопустимое извращение целей, которые должны направлять научнотехнический прогресс на благо человечества. Все государства сотрудничают в создании, укрепле- нии и развитии научно-технического потенциала развивающихся стран в целях ускорения осуществления социальных и экономических прав народами этих стран. Все государства принимают меры, направленные на то, чтобы все слои населения могли пользоваться благами науки и техники, и на защиту этих слоев как в социальном, так и в материальном плане, от отрицательных последствий, которые могут быть результатом неправильного применения достижений научно-технического прогресса, в том числе их неправильного применения с целью посягательства на права отдельного лица или группы лиц, особенно в отношении уважения частной жизни и защиты человеческой личности и её физической и интеллектуальной неприкосновенности. Все государства принимают необходимые меры, включая законодательные, в целях обеспечения того, чтобы использование достижений науки и техники способствовало наиболее полному осуществлению прав человека и основных свобод без какой бы то ни было дискриминации по признаку расы, пола, языка или религиозных убеждений. Все государства принимают эффективные меры, включая законодательные, в целях предотвращения и недопущения использования научно-технических достижений в ущерб правам человека и основным свободам и достоинству человеческой личности. Все государства принимают, когда это необходимо, меры с целью обеспечения законодательства, гарантирующего права и свободы человека в условиях научно-технического прогресса.

Влияние международного права на научнотехническую революцию выражается в том, что его нормы объективно содействуют использованию научно-технических достижений в интересах всех государств, ограничивают возможность такого использования одними странами в ущерб другим. Тем самым создается реальная возможность для равноправного научно-технического сотрудничества государств. Однако превращение этой возможности в реальность зависит от политической воли государств, соблюдения ими принципов и норм международного права [8]. Владимир Путин во время рабочей встречи с президентом Российской академии наук Александром Сергеевым по вопросу о характере международного научного сотрудничества сказал: «У нас здесь нет никаких ограничений, сотрудничать нужно со всеми, кто хочет с нами работать. Единственное, на что хотел бы обратить 
внимание: в результате работы, а она должна быть построена на равноправной основе, равноценном обмене, чтобы мы от этой работы ничего не проигрывали, а только выигрывали. Нужно к этому стремиться, чтобы мы не были просто источником получения каких-то наших навыков, знаний. Если мы делимся чем-то с кем-то, то мы должны получать равноценную информацию с обратной стороны» [9].

Последние годы отмечены становлением значительного числа норм, принятием международных соглашений и документов по этим вопросам. Они занимают важное место в современной международной практике. По-видимому, роль международного права будет возрастать и в будущем. Объясняется это, в частности, необходимостью правовой регламентации взаимоотношений государств в новых видах деятельности, вызванных к жизни техническим прогрессом, а также уменьшением как ресурсов, так и свободного пространства планеты в связи со значительным увеличением её населения и ростом потребления. Речь идет об увеличении всего объема общего международного права в целом, о расширении его многоплановости, углублении его содержания и усилении императивной значимости его норм [10]. Это общетеоретическое утверждение об увеличении массива международно-правовых норм справедливо и по отношению к международному научнотехническом сотрудничеству в двадцать первом веке. Одним из международно-правовых проявлений научно-технического прогресса является появление международных межправительственных организаций, например, Международный союз электросвязи, Всемирный почтовый союз, ЮНЕСКО и др.

Важную роль в создании благоприятных международно-правовых условий для научной деятельности играют институциональные механизмы защит прав интеллектуальной собственности. Например, на территории евразийского региона действует Евразийская патентная конвенция [11] (заключена в Москве 09.09.1994). Сторонами конвенции (договаривающиеся государства) являются Азербайджан, Армения, Беларусь, Грузия, Казахстан, Киргизия, Молдова, Россия, Таджикистан, Украина. Органами Организации являются Административный совет и Евразийское патентное ведомство (далее - Евразийское ведомство). Для выполнения административных задач, связанных с функционированием
Евразийской патентной системы и выдачей евразийских патентов, учреждена Евразийская патентная организация Евразийское ведомство возглавляет Президент, который является высшим должностным лицом Организации и представляет Организацию.

Евразийское ведомство выдает евразийский патент на изобретение, которое является новым, имеет изобретательский уровень и промышленно применимо. Право на евразийский патент принадлежит изобретателю или его правопреемнику. При этом, если изобретатель является служащим, то право на евразийский патент определяется в соответствии с законодательством государства, в котором служащий имеет основное место службы; если государство, в котором служащий имеет основное место службы, не может быть определено, применяется законодательство того государства, в котором работодатель занимается предпринимательской деятельностью, с которой связан служащий.

«Патентная инструкция к Евразийской патентной конвенции» (Утверждена 01.12.1995) (с изм. и доп. от 08.11.2010-10.11.2010) регулирует правоотношения, связанные с подачей евразийских заявок, их рассмотрением, выдачей евразийских патентов и охраной, предоставляемой евразийскими патентами в соответствии со статьями 14 и 19 Евразийской патентной конвенции и содержит детали, касающиеся материальных норм патентного права

Расширяются области и виды научнотехнического сотрудничества государств. При этом при осуществлении научно-технического сотрудничества используются различные формы и методы: обмен литературой и научными докладами, непосредственные контакты и связи между учеными; проведение международных и национальных конференций, симпозиумов, семинаров, курсов и других совещаний научнотехнического характера с участием в них ученых и специалистов нескольких стран; совместная разработка и осуществление программ и проектов; использование коммерческих каналов и методов для изучения и передачи передового научно-технического опыта и др. [12]

Для практического использования абсолютного большинства открытий нужно указание методов и приемов их использования, то есть нужно изобретение - продукт производственной практики и прикладной науки. Открытие есть установление, объяснение объективно су- 
ществующих закономерностей; изобретение есть конкретное предложение для практической деятельности с целью достижения определённого производственного результата. Изобретение всегда или в большинстве случае опирается на данные фундаментальной науки, на одно или несколько открытий [13].

у Российской Федерации имеется значительный потенциал в ряде областей фундаментальных научных исследований, что находит отражение в том числе в рамках совместных международных проектов, включая создание и использование уникальных научных установок класса «мегасайнс». Однако направления исследований и разработок в значительной степени соответствуют направлениям, актуальным для последних десятилетий прошлого века. Например, в швейцарском ЦЕРНе - главной лаборатории физики элементарных частиц - обнародовали сенсационные планы. Речь идет о строительстве нового ускорителя - почти в 4 раза больше, в 7 раз мощнее и во много раз дороже действующего БАКа - Большого андронного коллайдера. Однако только сейчас этот мегапроект наконец-то обрел видимые очертания: на сайте ЦЕРНа (Европейской организации по ядерным исследованиям со штаб-квартирой в Женеве) объявлено о подготовке четырехтомного доклада-концепции, посвященного БЦК. В докладе - ответы на все основные вопросы по проекту: от его научного потенциала до технических вызовов, стоимости и сроков реализации. Сам проект, кстати, стал международным ещё до рождения: только в работе над его концепцией приняли участие 1300 экспертов из 150 университетов, научных институтов и других организаций мира! Ну а в случае реализации он наверняка станет ещё одной знаковой международной научно коллаборацией и очередным доказательством, что наук становится все более интернациональной [14].

Можно также назвать следующие международные научные проекты, созданные при участии нескольких государств:

- Европейский центр ядерных исследований;

- Объединенный институт ядерных исследований;

- Международное агентство по изучению рака;

- Африканский центр риса;

- «Союз - Апполон»;
- Европейская молекулярно-биологическая лаборатория;

- Международный исследовательский институт продовольственной политики;

- Международная организация по изучению генома человека;

- MIRI - Machine Intelligence Research Institute;

- Проект международного экспериментального термоядерного реактора [15];

Международные отношения в широком смысле включают в себя многочисленные, разнородные и весьма важные отношения негосударственного характера - экономические, социальные, научно-технические, идеологические, политические, правовые, культурные, национальные, религиозные, социально-психологические, в том числе групповые, семейные, возможно даже индивидуальные. В этом смысле можно говорить о системе международных отношений в широком смысле [16].Среди примеров неправительственного международного научного сотрудничества можно назвать проходившую 13-16 ноября 2018 года в Париже 26-ую Генеральную конференцию по мерам и весам, утвердившей последнее обновление международной системы единиц, которая сегодня включает в себя 7 базовых величин: массу, длину, время, силу тока, температуру, количество вещества и силу света. Прежде для этих единиц измерения существовали свои первичные эталоны, как, например, платиноиридиевый слиток в роли точной меры одного килограмма. С помощью этих образцов производилась калибровка измерительных приборов. Но так как эталон может со временем подвергаться изменениям характеристик вещества под влиянием внешних факторов, впоследствии произошел переход к фундаментальным константам, неизменным для всего мироздания [17].

Для достижения цели научно-технологического развития Российской Федерации необходимо способствовать формированию модели международного научно-технического сотрудничества и международной интеграции в области исследований и технологического развития, позволяющей защитить идентичность российской научной сферы и государственные интересы в условиях интернационализации науки и повысить эффективность российской науки за счет взаимовыгодного международного взаимодействия. 
В соответствии с Указом Президента РФ от 01.12.2016 № 642 «О стратегии научно технологического развития Российской Федерации» международное научно-техническое сотрудничество и международная интеграция в области исследований и технологий, позволяющие защитить идентичность российской научной сферы и государственные интересы в условиях интернационализации науки и повысить эффективность российской науки за счет взаимовыгодного международного взаимодействия достигаются путем:

a) определения целей и формата взаимодействия с иностранными государствами в зависимости от уровня их технологического развития и инновационного потенциала;

б) формирования и продвижения актуальной научной повестки государства как участника международных организаций, повышения уровня участия России в международных системах научно-технической экспертизы и прогнозирования;

в) локализации на территории страны крупных международных научных проектов в целях решения проблем, связанных с большими вызовами;

г) развития механизма научной дипломатии как разновидности публичной дипломатии;

д) реализации скоординированных мер поддержки, обеспечивающих выход российских научных, образовательных организаций и производственных компаний на глобальные рынки знаний и технологий, а также проактивного участия России в разработке технологических стандартов и научно-образовательных форматов, способствующих повышению её роли в формировании новых рынков.

Вопрос «научной дипломатии» был одним из самых главных в предвыборной кампании Александра Сергеева летом 2017 года - он неоднократно повторял, что «наука должна наводить мосты» между странами [18]. Учитывая свой государственный статус, полномочия по формированию государственной научно-технической политики, свой международный авторитет, РАН должна инициировать новые направления международной деятельности в области фундаментальных и поисковых исследований, осуществлять поиск заинтересованных партнеров, способствовать расширению представительства нашей страны в международных организациях, активнее осваивать «новые географические на- правления. «Научная дипломатия» РАН должна помогать государственной дипломатии в сохранении и развитии связей России с зарубежными странами, препятствовать попыткам изолировать страну от использования современных достижений в науке и технологиях [19].

Воздействие НТП на международные отношения отразилось, естественно, на их главном регуляторе - международном праве, которое в значительной мере состоит из норм, созданных для обслуживания потребностей, порожденных научно-техническим прогрессом. Достаточно вспомнить, что институционализация международных отношений была вызвана прежде всего необходимостью организовать сотрудничество государств по использованию достижений науки и техники в области транспорта, связи и ряда других. С течением времени НТП охватывал все новые и новые сферы, росли число и разнообразие международных организаций, а также их роль в системе международно-правового регулирования [20].

Таким образом, концептуально международно-правовое регулирование научно-технического сотрудничества обеспечивает общие международные правовые условия развития науки и научной деятельности, целью которых выступает производство знаний для практического преобразования действительности и удовлетворения потребностей общества с учетом современных технологий.

Целостная современная международноправовая концепция международного научного и научно-технического сотрудничества, международной интеграции в области научных исследований и технологического развития и научной дипломатии может исходить из следующих предпосылок:

во-первых, равноправия как фундаментальный принцип сотрудничества;

во-вторых, наличия межгосударственного и неправительственного уровней научного взаимодействия;

в-третьих, закрепления академических свобод как гарантии осуществления научной деятельности;

в-четвертых, необходимости защиты прав интеллектуальной собственности на международном уровне;

в-пятых, тесной взаимосвязи науки, образования и промышленного производства. 


\section{Библиографический список}

1. Система, структура и процесс развития современных международных отношений. Издательство «Наука». M. 1984. C. 252.

2. Ю. С. Нехорошев, Ю.А. Тонких Наука и производительные силы общества // Известия Томского ордена Красного знамени политехнического института имени С. М. Кирова. 1967. Том 181. С. 38.

3. Режим доступа: https://undocs.org/ru/A/RES/70/1 (дата обращения 20.05.2019).

4. Ю. С. Нехорошев, Ю.А. Тонких Указ. соч. С. 39.

5. Пункт і) а) 1 Рекомендации ЮНЕСКО «О статусе научно-исследовательских работников» от 20 ноября 1974 года

6. М. И. Лазарев Технический прогресс и современное международное право //Советское государство и право. -1962. - № 12.- С. 102-110.

7. Резолюция 3384 Генеральной Ассамблеи ООН «Декларация об использовании научно-технического прогресса в интересах мира и на благо человечества» (Принята в г. Нью-Йорке 10.11.1975 на 2400-м пленарном заседании 30-й сессии Генеральной Ассамблеи ООН).

8. Йорыш А.И. Научно-технический прогресс и новые проблемы права.- М.: Междунар. отношения, 1982. C. 17.

9. Встреча с главой РАН Александром Сергеевым. Режим доступа: http://kremlin.ru/events/president/news/59648 (Дата обращения: 15 января 2019 г.).

10. Йорыш А.И. Указ соч. С. 15.

11. «Евразийская патентная конвенция» (Заключена в г. Москве 09.09.1994) // СПС «Консультант Плюс».

12. Йорыш А.И. Указ. соч. С. 17.

13. Ю. С. Нехорошев, Ю.А. Тонких Указ соч. С. 43.

14. Журнал «Огонёк» от 28.01.2019, стр. 29.

15. Журнал «Огонёк» от 07.10.2013, стр. 38.

16. Система, структура и процесс развития современных международных отношений. Издательство «Наука». M. 1984. C. 40.

17. Константин Ходаковский. Килограмм и ещё три базовые величины СИ изменят свои значения // 3DNews Daily Digital Digest от 16 ноября 2018.

18. Академики нашли область применения // Газета «Коммерсантъ» от 30.01.2019, стр. 1.

19. Материалы портала «Научная Россия». 21 сентября 2017. Программа кандидата в президенты Российской академии наук А. М. Сергеева.

20. Научно-технический прогресс и актуальные вопросы международного права / Н.Н. Ульянова, А.А. Шишко, Е.Т. Рулько и др.; отв. ред. Н.Н. Ульянова, А.А. Шишко; АН УССР. Ин-т государства и права.- Киев: Наук. думка, 1990. С. 3. 